\title{
Application of DNA Fingerprinting using the D1S80 Locus in Lab Classes
}

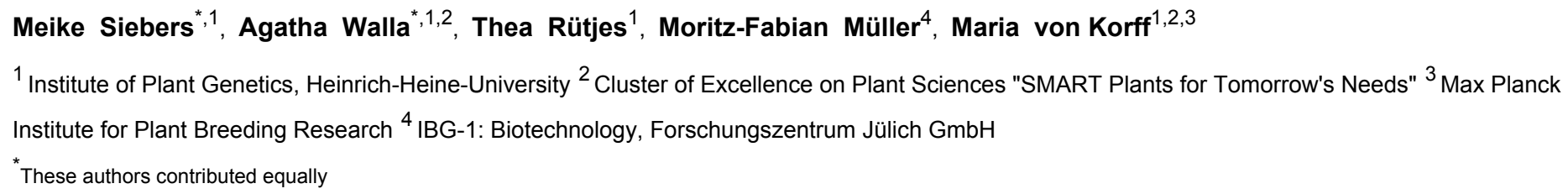

\section{Corresponding Author}

\section{Meike Siebers}

meike.siebers@hhu.de

\section{Citation}

Siebers, M., Walla, A., Rütjes, T., Müller, M.F., von Korff, M. Application of DNA Fingerprinting using the $D 1 S 80$ Locus in Lab Classes. J. Vis. Exp. (173), e62305, doi:10.3791/62305 (2021).

\section{Date Published}

July 17,2021

DOI

$10.3791 / 62305$

URL

jove.com/video/62305

\section{Abstract}

In biological sciences, DNA fingerprinting has been widely used for paternity testing, forensic applications and phylogenetic studies. Here, we describe a reliable and robust method for genotyping individuals by Variable Number of Tandem Repeat (VNTR) analysis in the context of undergraduate laboratory classes. The human D1S80 VNTR locus is used in this protocol as a highly polymorphic marker based on variation in the number of repetitive sequences.

This simple protocol conveys useful information for teachers and the implementation of DNA fingerprinting in practical laboratory classes. In the presented laboratory exercise, DNA extraction followed by PCR amplification is used to determine genetic variation at the D1S80 VNTR locus. Differences in the fragment size of PCR products are visualized by agarose gel electrophoresis. The fragment sizes and repeat numbers are calculated based on a linear regression of the size and migration distance of a DNA size standard.

Following this guide, students should be able to:

- Harvest and extract DNA from buccal mucosa epithelial cells

- Perform a PCR experiment and understand the function of various reaction components

- Analyze the amplicons by agarose gel electrophoresis and interpret the results

- Understand the use of VNTRs in DNA fingerprinting and its application in biological sciences 
Molecular fingerprinting, also referred to as DNA fingerprinting, was introduced by Sir Alec Jeffreys while working in the Department of Genetics at the University of Leicester in $1984^{1}$. It is based on the $0.1 \%$ of the human genome that differs between individuals and is comprised of approximately three million variants. These unique differences in the genotype allow for the differentiation between individuals and can therefore function as a genetic fingerprint except for monozygotic twins. Consequently, DNA fingerprinting is used for the estimation of relatedness of different individuals that is applied for example in paternity testing or in population diversity studies. In our laboratory classes we aimed to convey the concept of DNA fingerprinting and allele frequencies. The method described here demonstrates a reliable and robust method for genetic fingerprinting by analyzing the Variable Number of Tandem Repeats (VNTR) at the D1S80 locus. The method comprises the extraction of DNA from buccal mucosa epithelial cells and subsequent Polymerase Chain Reaction (PCR) to amplify the D1S80 locus, followed by visualization of fragment length differences on an agarose gel.

The D1S80 VNTR minisatellite locus is highly variable and located at the telomeric region of chromosome 1 (1p36p35). It was identified and described by Karsai and coworkers in 1990 as a locus with a core repeat unit of $16 \mathrm{bp}$, allowing for the separation of alleles differing by just one unit ${ }^{2}$. Furthermore, D1S80 shows a high degree of variation with a mutation rate of approximately $7.77 \times 10^{-5} 3$. D1S80 has a high degree of heterozygosity ${ }^{4,5}$ (e.g., $80.8 \%$ heterozygosity for Caucasians ${ }^{6}$ and up to $87 \%$ heterozygosity for AfricanAmericans ${ }^{7}$ ). Additionally, the $D 1 S 80$ locus is polymorphic in most populations, with typically over 15 different alleles carrying 14 to 41 repeats each. The frequency of $D 1 S 80$ alleles varies between populations. The allele with 24 repeat units (allele 24) is most frequent in European and Asian populations, whereas allele 21 is most common in African populations $4,7,8,9,10$. Consequently, the allele frequency distributions are diagnostic for different human populations and need to be taken into account for the estimation of relatedness (e.g., in paternity tests).

PCR based amplification of the D1S80 VNTR locus has been a very useful method in forensic science, paternity tests, disease analysis and population diversity studies ${ }^{11,12,13,14}$. While in forensics today the use of VNTRs has been replaced by short tandem repeats, the D1S80 VNTR locus is widely used in the determination of origins and genetic relations among and between populations s, $^{4,9,11}$. Furthermore, it is often used to teach DNA fingerprinting in practical laboratory classes $^{15,16}$. The method described here represents a robust, cost-effective and easy-to-use method with a very high success rate in undergraduate laboratory classes. The purpose of this article is to provide an overview of the workflow for the molecular analysis of the human D1S80 minisatellite locus from buccal mucosa epithelial cells. It includes demonstration of techniques, simplified protocols and practical suggestions described in previously published works ${ }^{2,17}$.

\section{Protocol}

NOTE: This protocol is only to be used if students or respective legal guardians agreed to the conductance of this protocol as genotypic profiles give insights into genetic relationships. DNA fingerprinting is a common molecular biology method mainly applied to population studies and forensic matters. Therefore, attention should be devoted to keep contamination risks as low as possible. To avoid contamination of the sample with DNA from an outside source or DNases, gloves should be worn, instruments should be 
thoroughly cleaned or sterilized and solutions should be filtersterilized or autoclaved before usage.

\section{Harvesting of buccal mucosa epithelial cells}

CAUTION: Work with saliva and epithelial cells can lead to a transmission of infectious diseases. Therefore, standard and transmission-based precautions should be applied (e.g., the use of appropriate personal protective equipment).

NOTE: Include a positive control, which is provided by the instructor (e.g., DNA extracted by the instructor) and included in the downstream processing steps.

1. Wait at least $1 \mathrm{~h}$ after eating or brushing teeth before specimen collection.

2. Label an empty and sterile $2.0 \mathrm{~mL}$ microcentrifuge tube.

3. Remove one sterile buccal swab from the packaging and rub vigorously on the inside of the cheek for 30-40 times or $30-40$ seconds to harvest buccal mucosa epithelial cells.

4. Place the tip of the collection swab into the previously labeled sterile microcentrifuge tube and break off the length of plastic that extends beyond the edge, either by hand or using sterile scissors.

5. Place the cap securely onto the tube, sealing the collection swab inside.

\section{Extraction of genomic DNA from human cells}

1. Before extraction, set a thermal mixer or a heating block to $65^{\circ} \mathrm{C}$ for sample lysis.

CAUTION: Some chemicals used are classified hazardous. Read the safety data sheet carefully and take appropriate safety measures before handling.
1. Prepare and sterilize by filtering or autoclaving all required buffers and solutions (lysis solution, $8 \mathrm{M}$ potassium acetate, 2-propanol, $70 \%$ ethanol and elution buffer).

NOTE: All centrifugation steps should be performed at room temperature $\left(20-30^{\circ} \mathrm{C}\right)$ unless specified.

2. Add $500 \mu \mathrm{L}$ of lysis solution $(50 \mathrm{mM}$ Tris/ $\mathrm{HCl}, \mathrm{pH} 8.0$; $10 \mathrm{mM}$ ethylenediamine tetra-acetic acid (EDTA); $\%$ sodium dodecyl sulfate (SDS)) to the buccal swab, making sure that the sample is completely immersed in the lysis solution.

1. Vortex vigorously for at least $5 \mathrm{~s}$.

2. Incubate samples at $65^{\circ} \mathrm{C}$ in a thermal mixer for 10 $\min$.

3. Mix sample 3-4 times by pulse-vortexing for $5 \mathrm{~s}$ during incubation.

4. Remove swab from the lysis buffer, press the swab against the inside of the tube to obtain maximum sample volume.

3. Add $100 \mu \mathrm{L}$ of $8 \mathrm{M}$ potassium acetate to lysed cells.

1. Mix thoroughly by inverting the tube until there is a white precipitate.

2. Incubate for $5 \mathrm{~min}$ at room temperature.

4. Centrifuge the sample for $5 \mathrm{~min}$ at $18,000 \times \mathrm{g}$.

5. Transfer $450 \mu \mathrm{L}$ of the supernatant into a clean and sterile $1.5 \mathrm{~mL}$ microcentrifuge tube.

6. Add $450 \mu \mathrm{L}$ of 2-propanol and mix thoroughly by inverting the tube (precipitation of the DNA).

7. Incubate for $5 \mathrm{~min}$ at room temperature.

8. Centrifuge for $5 \mathrm{~min}$ at $18,000 \times \mathrm{g}$. 
9. Discard the supernatant and invert the tube on a clean paper towel to dry the pellet and to avoid crosscontamination.

10. Incubate the DNA for $5 \mathrm{~min}$ at $65{ }^{\circ} \mathrm{C}$ in a heating block to dry the pellet completely.

11. To wash the DNA, add $500 \mu \mathrm{L}$ of $70 \%$ ethanol.

12. Centrifuge for $1 \mathrm{~min}$ at $18,000 \times \mathrm{g}$.

13. Discard the supernatant and invert the tube on a clean paper towel to dry the pellet.

14. Add $30 \mu \mathrm{L}$ of resuspension buffer $(10 \mathrm{mM}$ Tris $/ \mathrm{HCl} \mathrm{pH}$ 8.0, $1 \mathrm{mM}$ EDTA) to the pellet.

15. Incubate the DNA for $10 \mathrm{~min}$ at $65^{\circ} \mathrm{C}$ in a heating block to inactivate DNases.

\section{Amplifying the D1S80 VNTR locus using PCR}

NOTE: Record the number of samples that will be used and prepare a worksheet with the required reagents and their volumes before collecting the necessary plastics and other materials. Label the sterile tubes/strips/plates to be used for the PCR with sample numbers. Remember to include a negative control using $\mathrm{H}_{2} \mathrm{O}$ instead of DNA and a positive control (e.g., using the DNA provided by the instructor) to validate the PCR.

1. Prepare the $1 x$ PCR master mix containing 10 $\mu \mathrm{L}$ of $5 \mathrm{x}$ PCR reaction buffer (containing $15 \mathrm{mM}$ $\mathrm{MgCl}_{2}$ ), $1 \mu \mathrm{L}$ of deoxyribonucleotide triphosphate (dNTPs) $(10 \mathrm{mM}), \quad 5 \mu \mathrm{L} \quad(10 \mathrm{pmol})$ of each primer pMCT118-f and pMCT118-r (forward - 5'GAAACTGGCCTCCAAACACTGCCCGCCG-3', reverse

- 5'-GTCTTGTTGGAGATGCACGTGCCCCTTGC-3') according to Kasai et al. ${ }^{2}, 23.8 \mu \mathrm{L}$ of ultrapure $\mathrm{H}_{2} \mathrm{O}$, and $0.2 \mu \mathrm{L}$ of Taq DNA polymerase $(5 \mathrm{U} / \mu \mathrm{L})$.
NOTE: The primers pMCT118-f/pMCT118-r were designed on the flanking regions of the D1S80 VNTR region amplifying the whole locus.

2. Label the PCR tubes/strips/plate with the sample numbers to be used.

3. Aliquot $45 \mu \mathrm{L}$ of the master mix to each labeled PCR sample tube or well.

4. Add $5 \mu \mathrm{L}$ of the DNA template to the master mix in each PCR tube/plate well to acquire a total volume of $50 \mu \mathrm{L}$. Change the pipette tip for every DNA sample to avoid cross contamination.

5. Include a no template control (NTC) by using ultrapure $\mathrm{H}_{2} \mathrm{O}$ instead of DNA.

6. Close PCR tubes/strips or seal plate and mix.

7. Centrifuge the PCR tubes/strips/plates for $20 \mathrm{~s}$ using a tabletop centrifuge.

NOTE: PCR conditions given in this protocol were optimized using the DNA polymerase and the PCR thermal cycler used. In general, PCR conditions must be adapted to the DNA polymerase. The standard extension time for a Taq DNA polymerase is $1 \mathrm{~min} / \mathrm{kb}$.

8. Place the sample tubes/strips/plate in the thermocycler and incubate reactions using the following conditions (DNA polymerase extension time): 1 cycle of $95^{\circ} \mathrm{C}$ for 2 min; 25 cycles of $94^{\circ} \mathrm{C}$ for $15 \mathrm{~s}, 60^{\circ} \mathrm{C}$ for $15 \mathrm{~s}, 72^{\circ} \mathrm{C}$ for $30 \mathrm{~s} ; 1$ cycle of $72{ }^{\circ} \mathrm{C}$ for $10 \mathrm{~min}$.

9. When the program is complete, remove the products from the thermocycler and store at $4{ }^{\circ} \mathrm{C}$ overnight or -20 ${ }^{\circ} \mathrm{C}$ until electrophoresis.

\section{Agarose gel electrophoresis of PCR products}

1. Prepare a $1.5 \%$ agarose gel. 
1. Use $1.5 \mathrm{~g}$ of agarose powder and mix it with $100 \mathrm{~mL}$ of $1 x$ Tris-acetate-EDTA (TAE) buffer solution in a flask.

2. Heat the mixture for about $1.5-2 \mathrm{~min}$ in a microwave oven (600 W). Swirl the contents and heat again, if necessary, to completely dissolve the agarose. Cool slightly and add $2 \mu \mathrm{L}$ of PeqGreen to the agarose.

3. Pour the gel in a form using a comb with enough wells for all samples and add at least one molecular weight marker.

CAUTION: Boiling retardation may occur. Shake the flask carefully when resuspending the agarose which has not been dissolved yet.

NOTE: PeqGreen is a non-toxic dye for the detection of nucleic acids. It is applicable for staining of double-stranded DNA (dsDNA) and single-stranded DNA (ssDNA) as well as RNA. The sensitivity is comparable to ethidium bromide.

2. Remove the PCR products from $4{ }^{\circ} \mathrm{C}$ and centrifuge for about $10 \mathrm{~s}$.

3. Load the wells of the gel with $10 \mu \mathrm{L}$ sample. Do not overload the gel.

NOTE: The DNA polymerase buffer also includes compounds that increases sample density so that samples can be loaded directly onto gels without the need for a loading dye. This allows the sample to sink into the well and dyes help to track how far the DNA sample has migrated.

1. Add a molecular weight standard to the flanking wells (preferably a $50 \mathrm{bp}$ molecular weight standard).
NOTE: Store the residual PCR samples at $-20^{\circ} \mathrm{C}$ in case the agarose gel electrophoresis has to be repeated.

4. Run the gel in $1 \times$ TAE running buffer at $150 \mathrm{~V}$ (constant) for approximately $40 \mathrm{~min}$ or until the lower yellow dye front that travels at around $50 \mathrm{bp}$ reaches the lower end of the gel.

5. Image the gel while blue light or ultraviolet (UV) light is applied and record an image for fragment length analysis.

CAUTION: UV light can damage your eyes and skin. Always wear protective clothing and UV safety glasses when using a UV light box.

6. Dispose the gel in accordance with the institutional hazardous materials policy.

\section{Analysis of fragment length results}

NOTE: Use linear regression analysis to estimate the lengths of the fragments.

1. For sizing the $D 1 S 80 \mathrm{PCR}$ fragments, place a ruler on the gel photograph over the $50 \mathrm{bp}$ molecular weight standard lane such that the top of the ruler lines up with the bottom of the well into which the sample was loaded (Figure 1). NOTE: To calculate the linear regression equation for the molecular weight standard $(50 \mathrm{bp}$ molecular weight standard) a spreadsheet program was used.

2. Record the distance from the well (e.g., in $\mathrm{cm})$ for each band of the $50 \mathrm{bp}$ molecular weight standard in a table using a spreadsheet program (Figure 2).

3. Determine the log (e.g., base 10) of each fragment size of the $50 \mathrm{bp}$ molecular weight standard and enter the log values into the table (Figure 2). 
4. Plot each data point to a graph with the log of the band sizes on the vertical axis (y-axis) and the measured run distance from the top of the gel to each band of the molecular weight standard on the horizontal axis (x-axis) using a scatterplot (Figure 3).

5. Fit a trendline (linear regression line) and show the regression equation $(y=a x+b)$ and the $R^{2}$ value on the graph (Figure 4).

6. Measure the distance migrated (e.g., in $\mathrm{cm}$ ) for each D1S80 amplicon (Figure 5).

7. Estimate the size of each D1S80 amplicon using the regression equation: $y=a x+b$

where $y=$ the $\log$ of the fragment size

$a=$ the slope of the line (calculated in point 5)

$\mathrm{x}=$ the distance from the well $($ in $\mathrm{cm}$ )

$b=$ the point where the regression line intercepts the $y$-axis (calculated in point 5)

NOTE: Since the $y$-value represents the log of the fragment size, the antilog $\left(10^{y}\right)$ must be calculated to obtain the fragment size in bp of the D1S80 amplicons.

\section{Estimation of the number of repeat units in the alleles of the tested individuals}

NOTE: The $D 1 S 80$ repeat unit is 16 bp in length. The smallest known allele for $D 1 S 80$ has 14 repeats. The amplicon scheme described here produces amplicons with flanking regions adding up an extra $145 \mathrm{bp}$ to the final size.

1. Use Table 1 to estimate how many repeat units are contained in each PCR fragment. The size extrapolated using the linear regression should be within $8 \mathrm{bp}$ of any particular allele.

2. Record the genotype of each tested individual as a combination of allele repeat size numbers.

\section{Representative Results}

Using the described protocol, D1S80 VNTR marker analysis was performed on human genomic DNA extracted from buccal mucosa epithelial cells harvested by swab sampling (Figure 6). Following the amplification using PCR, a typical representation of an agarose gel containing the D1S80 amplicons is shown in Figure 1. Lane 1 shows the $50 \mathrm{bp}$ molecular weight standard. Next to the molecular weight standard, PCR products from eight student samples are visualized. Lane 10 shows the NTC in which water was used instead of template DNA. Most of the analyzed samples clearly display two bands, representing individuals heterozygous for the D1S80 locus. Lane 2 and Lane 9 show a single band representing individuals homozygous for the D1S80 locus. Lane 5 is showing an ambiguous single band which is much wider compared to the other bands. This could be a result of two D1S80 alleles differing in only one repeat unit. For further analysis, the sample in lane 5 will be considered as a single band, representing a homozygous individual.

Downstream gel electrophoresis fragment analysis performed on verified PCR products was used for size calling of the D1S80 VNTR locus of different student samples. Interpretation of the amplicon sizes obtained by PCR analysis relies on the molecular weight standard used. The distance from the well for each band of the molecular weight standard was measured (Figure 1) and recorded (Figure 2). Based on the size and migration distance the size of the individual bands can be calculated using a linear regression analysis. The log (base 10) was determined for each band in the student samples (Figure 5) and the respective antilog represents the number of bp for each amplicon. The number 
of repeat units can be calculated according to the amplicon size obtained (Table 2).

For each student sample the amplicon sizes were calculated by linear regression and each band could be easily assigned to a particular allele as shown in Table 2. The information on the $D 1 S 80$ allele sizes can then be used to determine allele frequencies amongst the small population subset of undergraduate students. The 28-repeat allele is the most frequent among the students due to two homozygous individuals for this repeat allele (individuals 1 and 4 ). The second most frequent allele is the 18-repeat allele, which is carried by the homozygous individual 8 and by the heterozygous individual 6. Low frequency alleles are the 21-, 26- and 30-repeat alleles found only once in individuals 6,5 and 3 , respectively. The allele frequency patterns of the D1S80 VNTR locus of the small student population can further be compared to the allele frequency of larger human populations, for example populations originating from different continents $4,7,8,9,10$.

Among the students, individuals 2 and 3 share the 24-repeat allele, individuals 2 and 7 share the 20-repeat allele and individuals 5 and 7 share the 23-repeat allele. Interestingly, the two D1S80 homozygous individuals (individual 1 and 4) share the 28-repeat allele. Matching alleles between two individuals can indicate a potential relatedness. However, shared alleles can also occur by chance. Thus, it is crucial to determine the likelihood of an allele match between two individuals. The likelihood depends on the allele frequency of individual alleles in the general population and statistical approaches should be employed to attach a statistical weight to VNTR marker analysis such as the Bayesian approach. In summary, the presented fingerprinting method can be utilized in hands-on class practicals to teach the use of VNTRs in DNA fingerprinting and its application in biological science. 


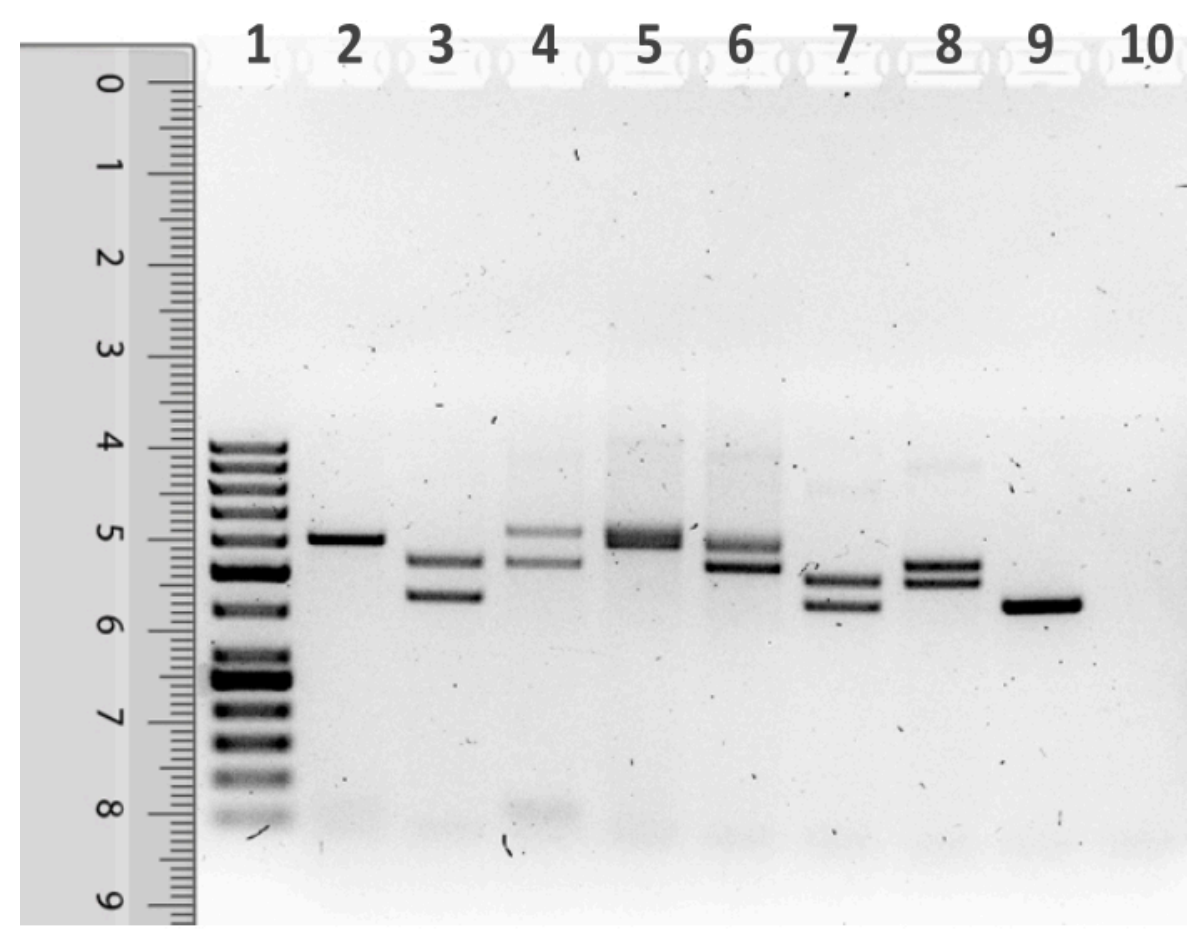

Figure 1: Representation of an agarose gel after electrophoresis of $D 1 S 80$ amplification products with a ruler placed beside the $50 \mathrm{bp}$ molecular weight standard lane. Lane 1 contains the $50 \mathrm{bp}$ molecular weight standard, while lanes 2-9 contain PCR reaction products. Lane 10 contains the no template control (NTC). Please click here to view a larger version of this figure. 


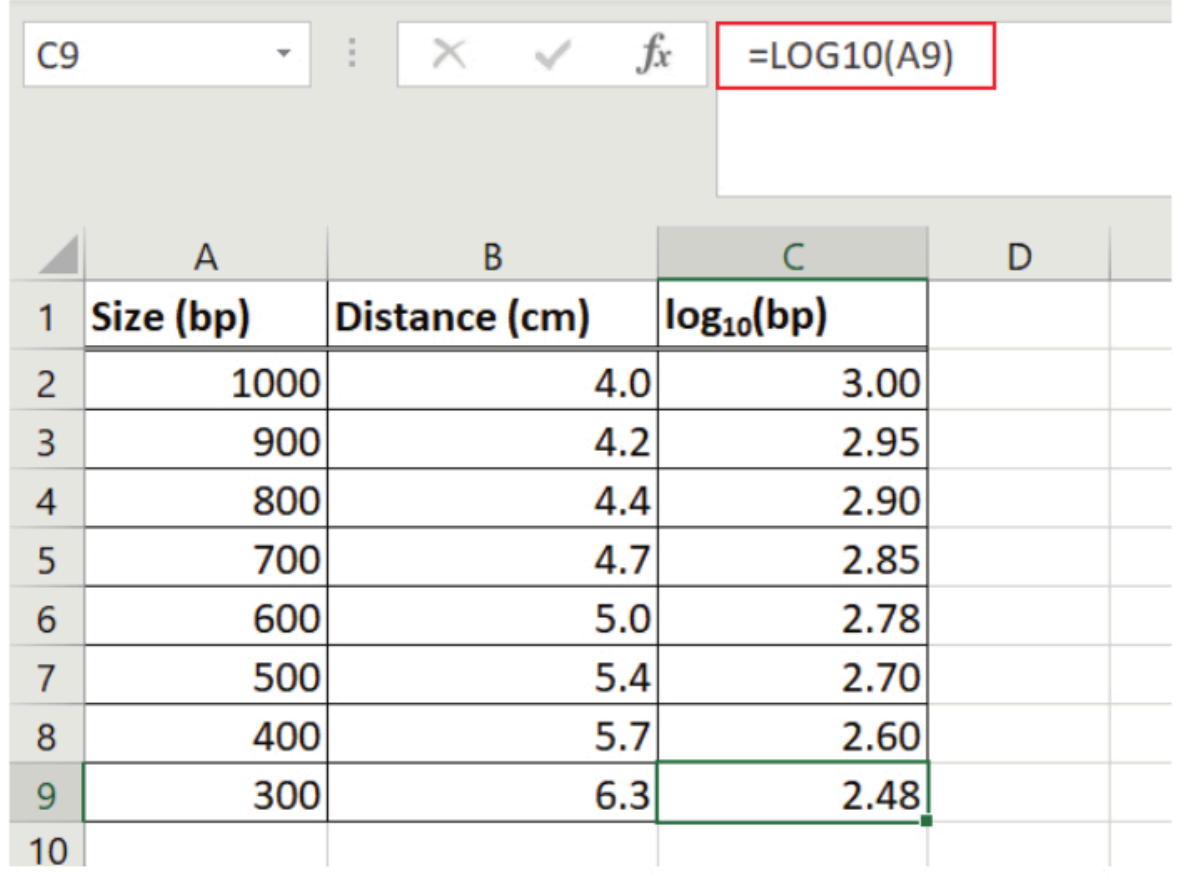

Figure 2: Determination of DNA fragment migration distance and log of each fragment size of the 50 bp molecular weight standard. The distance from the well (in $\mathrm{cm}$ ) for each band of the $50 \mathrm{bp}$ molecular weight standard is recorded and the log (base 10) for each fragment is determined. Values are entered into a table using a spreadsheet program. Please click here to view a larger version of this figure. 


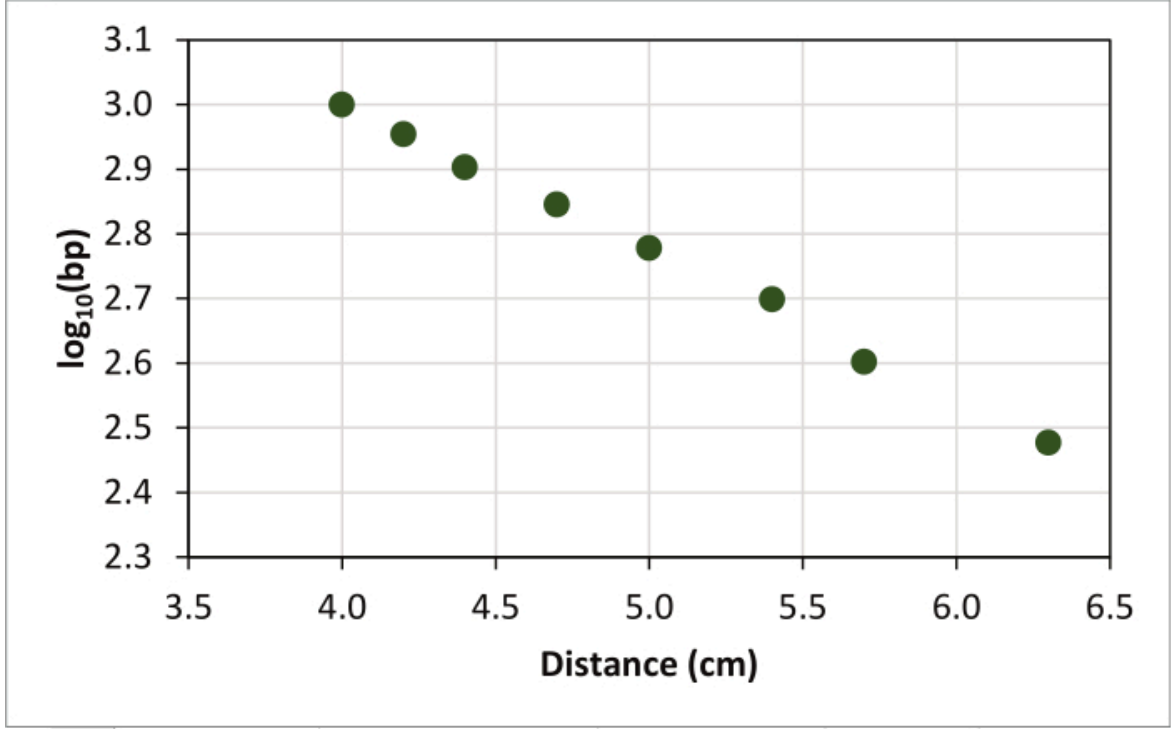

Figure 3: Scatter plot generated by plotting DNA fragment migration distance of the molecular weight standard on the $x$-axis against the log (base 10) of the size of each fragment on the $\mathbf{y}$-axis. Please click here to view a larger version of this figure.

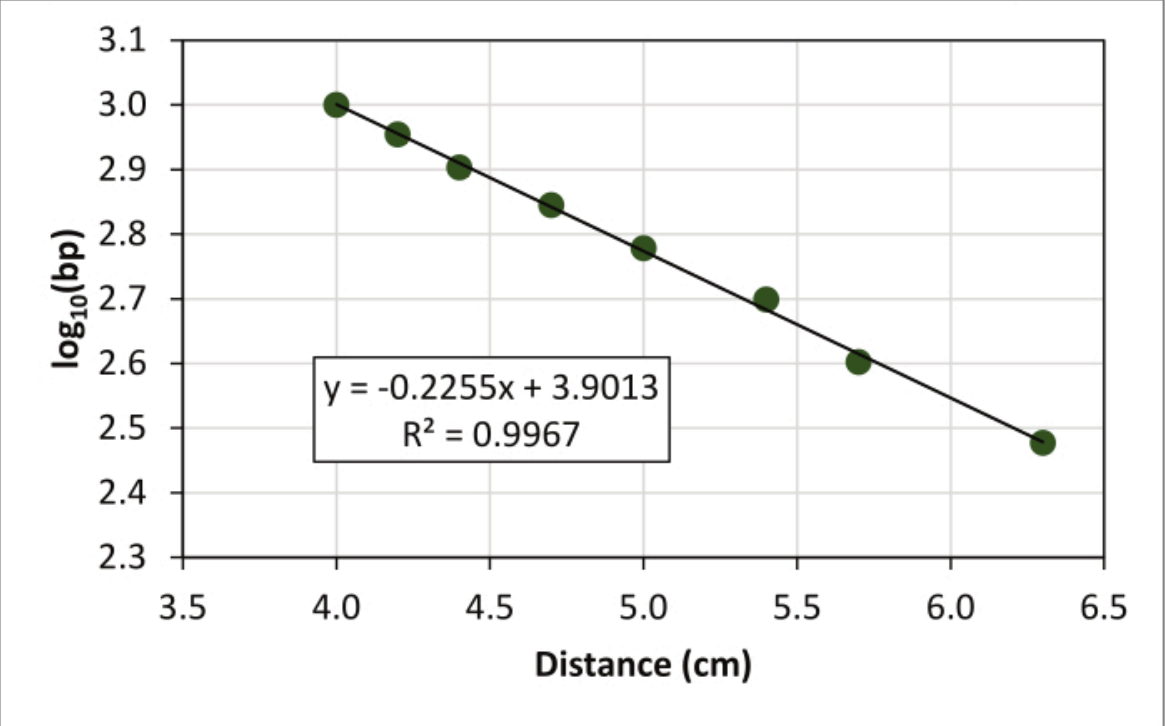

Figure 4: Exploitation of the linear regression line and regression equation as well as the $\mathrm{R}^{2}$ value for the data.

Please click here to view a larger version of this figure. 


\begin{tabular}{|c|c|c|c|c|c|c|}
\hline \multicolumn{2}{|c|}{ SUM } & \multirow{2}{*}{$\begin{array}{l}X \\
B\end{array}$} & $f_{x}$ & \multicolumn{2}{|c|}{$=10^{\wedge}\left(-0.2255^{*}(\mathrm{D} 10)+3.9013\right)$} & \multirow[b]{2}{*}{$\mathrm{F}$} \\
\hline$\triangle$ & A & & C & D & $\mathrm{E}$ & \\
\hline 1 & \multirow[b]{2}{*}{ Individual } & \multirow[b]{2}{*}{ Allele } & \multicolumn{2}{|c|}{ Distance from well (in cm) } & & \\
\hline 2 & & & Allele 1 & Allele 2 & Allele 1 & Allele 2 \\
\hline 3 & 1 & homozygous & 5 & 5 & 600 & 600 \\
\hline 4 & 2 & heterozygous & 5.2 & 5.5 & 535 & 458 \\
\hline 5 & 3 & heterozygous & 4.9 & 5.2 & 626 & 535 \\
\hline 6 & 4 & homozygous & 5 & 5 & 600 & 600 \\
\hline 7 & 5 & heterozygous & 5.1 & 5.3 & 564 & 508 \\
\hline 8 & 6 & heterozygous & 5.4 & 5.6 & 483 & 435 \\
\hline 9 & 7 & heterozygous & 5.3 & 5.5 & 508 & 458 \\
\hline 10 & 8 & homozygous & 5.6 & 5.6 & 435 & $3.9013)$ \\
\hline
\end{tabular}

Figure 5: Determination of the size of the D1S80 amplicons. The distance from the well for each fragment is entered into the regression equation. The antilog of the $y$-value represents the fragment size in bp. Please click here to view a larger version of this figure. 


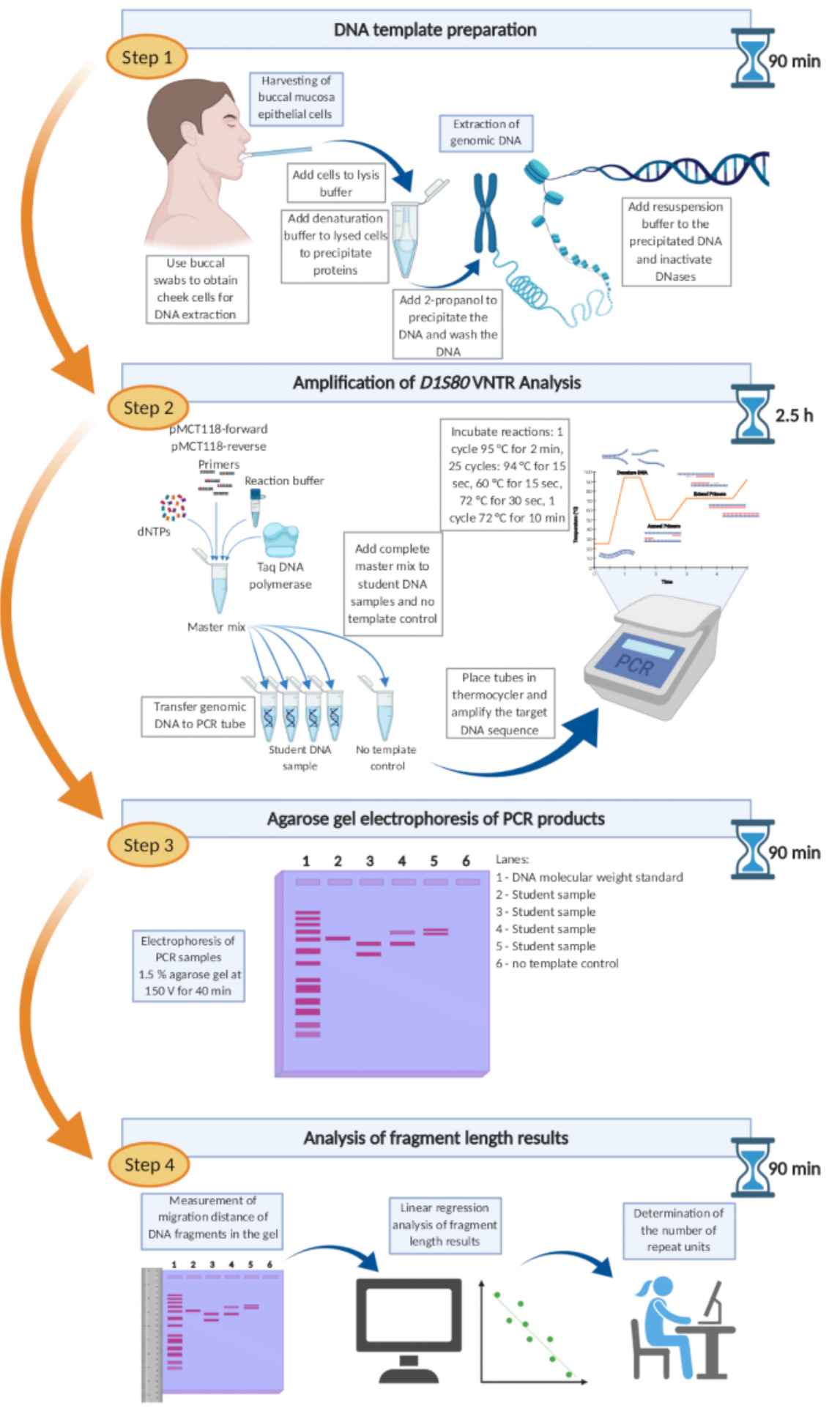


Figure 6: Suggested timeline and workflow for D1S80 VNTR analysis. The entire D1S80 VNTR analysis procedure presented here, from buccal epithelial cell harvesting to fragment length evaluation, may be completed within a single working day. Please click here to view a larger version of this figure. 


\begin{tabular}{|c|c|}
\hline Allele size (in bp) & Number of repeats \\
\hline 369 & 14 \\
\hline 385 & 15 \\
\hline 401 & 16 \\
\hline 417 & 17 \\
\hline 433 & 18 \\
\hline 449 & 19 \\
\hline 465 & 20 \\
\hline 481 & 21 \\
\hline 497 & 22 \\
\hline 513 & 23 \\
\hline 529 & 24 \\
\hline 545 & 25 \\
\hline 561 & 26 \\
\hline 577 & 27 \\
\hline 593 & 28 \\
\hline 609 & 29 \\
\hline 625 & 30 \\
\hline 641 & 31 \\
\hline 657 & 32 \\
\hline 673 & 33 \\
\hline 689 & 34 \\
\hline 705 & 35 \\
\hline 721 & 36 \\
\hline 737 & 37 \\
\hline 753 & 38 \\
\hline 769 & 39 \\
\hline
\end{tabular}


801

Table 1: Amplicon size for each D1S80 VNTR locus.

\begin{tabular}{|c|c|c|c|c|}
\hline Individual & Allele & Distance (in cm) & Size (in bp) & $\begin{array}{c}\text { Number of } \\
\text { repeat units }\end{array}$ \\
\hline 1 & homozygous & 5 & 600 & 28 \\
\hline 2 & heterozygous & $5.2 ; 5.5$ & 535,458 & 24,20 \\
\hline 3 & heterozygous & $4.9 ; 5.2$ & 626,535 & 28,24 \\
\hline 4 & homozygous & 5 & 600 & 26,23 \\
\hline 5 & heterozygous & $5.1 ; 5.3$ & 564,508 & 21,18 \\
\hline 6 & heterozygous & $5.4 ; 5.6$ & 483,435 & 23,20 \\
\hline 7 & heterozygous & $5.3 ; 5.5$ & 508,458 & 18 \\
\hline
\end{tabular}

Table 2: Allele composition of the different individuals tested. The number of repeat units can be approximated according to the amplicon size obtained by linear regression analysis.

\section{Discussion}

Here we described a simple and cost-efficient method for implementing molecular fingerprinting in undergraduate practical classes.

To screen for genetic variation at the D1S80 locus, human biological sample collection along with DNA extraction and analysis is required. It is essential that the ethical use of human biological specimens is ensured throughout the whole process. Sample management is controlled within a comprehensive regulatory framework which ensures the correct use of samples and associated data ${ }^{18}$ (e.g., consent for the use of human biological material). Participants must be properly informed about the use of their samples, the risk of discovery of anomalies in genetic relations (e.g., for related individuals), privacy protection and intentions for future storage of the biological specimens and data. All donors (students or colleagues) must give consent freely and understand the right to withdraw without giving reason. In general, it is indispensable to make oneself familiar with the respective guidelines and regulations for human sample management before conducting this lab class.

For the collection of buccal mucosa epithelial cells in undergraduate laboratory courses, care must be taken to avoid contamination of the DNA samples with DNA from the operator or with DNases. It is recommended that lab coats, gloves and protective glasses are always used as 
well as sterile swabs and microcentrifuge tubes. Buccal swab-based cell harvesting is considered a convenient and cost-effective method for the collection of genetic material suitable for PCR-based VNTR analysis, as it is relatively inexpensive and noninvasive. Beside buccal swabs, saliva is the most common oral sampling method for medical research. It has been shown that buccal swabs contain a higher proportion of epithelial cells than saliva, making them more reliable in providing sufficient quantity and quality of DNA for PCR-based D1S80 VNTR analysis ${ }^{19,20}$. Additionally, buccal swabs can be mailed out after selfcollection overcoming geographical impediments when used, for example, in population diversity studies ${ }^{21}$.

DNA extraction has become relatively easy due to the development of extraction kits from different companies. Nevertheless, the use of those kits may not be suitable in laboratory classes due to limited financial resources. Here, we presented an easy, fast and cost-efficient method for DNA extraction from human samples without the need of a commercially available DNA extraction kit. The DNA extraction method described does not use organic solvents, instead cellular proteins are removed by increasing the salt concentration using an $8 \mathrm{M}$ potassium acetate solution. This method also allows for handling of several samples at once and yields in sufficient DNA for several genotype analyses for each sample.

$\mathrm{PCR}$ is a common technique in many molecular laboratories. While generally trouble-free, there are pitfalls that may complicate the reaction producing spurious results, which have been discussed elsewhere ${ }^{22}$. PCR conditions presented here have appeared very robust in the face of poor template DNA quality, but lack of PCR amplification was nevertheless occasionally observed when using templates with extremely low DNA concentrations due to poor buccal epithelial cell harvesting. The DNA primers used in this study can be ordered from different companies, such as those cited in the table of materials at the end of this paper. Special care must be taken when working with DNA primers in order to avoid contamination with DNases or DNA from the operator. PCR products should also be kept cold when not in use.

Another critical step is the agarose gel electrophoresis. Fragments differing by only one repeat unit of 16 bp may not be separated in the gel electrophoresis and thus appear as a single band. In this case, a proper determination of the number of repeat units of the D1S80 alleles tested cannot be assured. Therefore, the run time of the gel should be increased while the voltage must be reduced and the gel concentration may be increased to provide a better resolution and separation of the single bands.

It is worth mentioning that not all alleles for an VNTR locus contain complete repeat units. Non-consensus alleles (microvariants) that contain incomplete repeat units are common at most VNTR loci and their sizes fall in between sizes of alleles with full repeat units. These microvariants are barely detectable by agarose gel electrophoresis. In contrast, techniques like polyacrylamide gels or capillary electrophoresis can resolve alleles that differ by one to a few repeat units or microvariants $12,23,24,25,26$. However, the latter techniques are less suitable for undergraduate laboratory classes as they have many disadvantages including use of hazardous compounds, complex preparation and lack of equipment. For the fragment size determination, special care must be taken when measuring the distance of the migrated DNA fragments. If the bands are too diffuse to be measured precisely, the calculation of the D1S80 allele fragment size by linear regression may be incorrect resulting 
in the wrong estimation of repeat unit numbers. In that case a re-run of the agarose gel electrophoresis after optimizing the gel conditions is advisable as previously described by Lorenz and co-workers ${ }^{22}$.

The entire D1S80 VNTR analysis procedure presented here, from buccal epithelial cell harvesting to fragment length evaluation, may be completed in a single working day. This protocol is a robust, cost-efficient and easy-to-use method suitable for undergraduate practical laboratory classes.

\section{Disclosures}

The authors have no conflict of interest to disclose.

\section{Acknowledgments}

The authors would like to thank Kevin Graham for his voiceover and all participants who donated samples for this work.

\section{References}

1. Jeffreys, A.J., Wilson, V., Thein, S.L. Hypervariable 'minisatellite' regions in human DNA. Nature. 314 (6006), 67-73 (1985).

2. Kasai, K., Nakamura, Y., White, R. Amplification of a variable number of tandem repeats (VNTR) locus (pMCT118) by the polymerase chain reaction (PCR) and its application to forensic science. Journal of Forensic Science. 35 (5), 1196-1200 (1990).

3. Balamurugan, K., Tracey, M.L., Heine, U., Maha, G.C., Duncan, G.T. Mutation at the human D1S80 minisatellite locus. The Scientific World Journal. 2012 (917235) (2012).

4. Herrera, R.J., Adrien, L.R., Ruiz, L.M., Sanabria, N.Y., Duncan, G. D1S80 single-locus discrimination among
African populations. Human Biology. 76 (1), 87-108 (2004).

5. Lauritzen, S.L., Mazumder, A. Informativeness of genetic markers for forensic inference - An information theoretic approach. Forensic Science International: Genetics Supplement Series. 1 (1), 652-653 (2008).

6. Budowle, B., Chakraborty, R., Giusti, A.M., Eisenberg, A.J., Allen, R.C. Analysis of the VNTR locus D1S80 by the PCR followed by high-resolution PAGE. American Journal of Human Genetics. 48 (1), 137 (1991).

7. Budowle, B. et al. D1S80 population data in African Americans, Caucasians, southeastern Hispanics, southwestern Hispanics, and Orientals. Journal of Forensic Science. 40 (1), 38-44 (1995).

8. Verbenko, D.A. et al. Polymorphisms at locus D1S80 and other hypervariable regions in the analysis of Eastern European ethnic group relationships. Annals of Human Biology. 33 (5-6), 570-584 (2006).

9. Walsh, S.J., Eckhoff, C. Australian Aboriginal population genetics at the D1S80 VNTR locus. Annals of Human Biology. 34 (5), 557-565 (2007).

10. Limborska, S.A., Khrunin, A. V, Flegontova, O. V, Tasitz, V.A., Verbenko, D.A. Specificity of genetic diversity in D1S80 revealed by SNP-VNTR haplotyping. Annals of Human Biology. 38 (5), 564-569 (2011).

11. Sajib, A.A., Yeasmin, S., Akter, M., Uddin, M.A., Akhteruzzaman, S. Phylogenetic analysis of Bangladeshi population with reference to D1S80 VNTR locus. Bioresearch Communications. 2 (1), 146-151 (2016). 
12. Köseler, A., Atalay, A., Atalay, E.Ö. Allele frequency of VNTR locus D1S80 observed in Denizli province of Turkey. Biochemical genetics. 47 (7-8), 540-546 (2009).

13. Mastana, S.S., Papiha, S.S. D1S80 distribution in world populations with new data from the UK and the Indian sub-continent. Annals of Human Biology. 28 (3), 308-318 (2001).

14. Okuda, H. et al. A Japanese propositus with D-phenotype characterized by the deletion of both the RHCE gene and D1S80 locus situated in chromosome $1 p$ and the existence of a new CE-D-CE hybrid gene. Journal of Human Genetics. 45 (3), 142-153 (2000).

15. Campbell, A.M., Williamson, J.H., Padula, D., Sundby, S. Use PCR \& a Single Hair to Produce a "DNA Fingerprint." The American Biology Teacher. 59 (3), 172-178 (1997).

16. Jackson, D.D., Abbey, C.S., Nugent, D. DNA profiling of the D1S80 locus: A forensic analysis for the undergraduate biochemistry laboratory. Journal of Chemical Education. 83 (5), 774 (2006).

17. Mansoor, S.K., Hussein, E.F., Ibraheem, A.K. Use the Variable Number of Tandem Repeats (VNTR) in DNA fingerprinting and its application biological sciences. EurAsian Journal of BioSciences. 14 (2), 2835-2839 (2020).

18. Beier, K., Schnorrer, S., Hoppe, N., Lenk, C. The ethical and legal regulation of human tissue and biobank research in Europe - Proceedings of the Tiss. EU Project. Universitätsverlag Göttingen. (2011).

19. Aida, J. et al. Telomere length variations in 6 mucosal cell types of gastric tissue observed using a novel quantitative fluorescence in situ hybridization method. Human Pathology. 38 (8), 1192-1200 (2007).
20. Theda, C. et al. Quantitation of the cellular content of saliva and buccal swab samples. Scientific Reports. 8 (1), 1-8 (2018).

21. McMichael, G.L. et al. DNA from buccal swabs suitable for high-throughput SNP multiplex analysis. Journal of biomolecular techniques: JBT. 20 (5), 232 (2009).

22. Lorenz, T.C. Polymerase chain reaction: basic protocol plus troubleshooting and optimization strategies. Journal of Visualized Experiments. 63 (63), e3998 (2012).

23. Destro-Bisol, G., Capelli, C., Belledi, M. Inferring microevolutionary patterns from allele-size frequency distributions of minisatellite loci: a worldwide study of the APOB 3'hypervariable region polymorphism. Human Biology. 72 (5), 733-751 (2000).

24. Chen, B. et al. Structure and function of alleles in the 3 'end region of human apoB gene. Chinese Medical Journal. 112 (3), 221-223 (1999).

25. Renges, H.-H., Peacock, K., Dunning, A.M., Talmud, P., Humphries, S.E. Genetic relationship between the 3 '-VNTR and diallelic apolipoprotein B gene polymorphisms: Haplotype analysis in individuals of European and South Asian origin. Annals of Human Genetics. 56 (1), 11-33 (1992).

26. Kravchenko, S.A., Maliarchuk, O.S., Livshits, L.A. A population genetics study of the allelic polymorphism in the hypervariable region of the apolipoprotein $B$ gene in the population of different regions of Ukraine. Tsitologiia i Genetika. 30 (5), 35-41 (1996). 